THE principal gifts that followed were the Blatch collection of Lepidoptera, presented by Sir George Kenrick ; a collection of British and foreign bird-skins by Mr. Walter Chamberlain ; the Scott collection of British birds and foreign Lepidoptera, from Mrs. Adrian Hope and Mrs. Farnham; the Bradley collection of Hymenoptera, Diptera, Lepidoptera, etc., from Mr. A. R. Hollinsworth; the herbarium of British plants from Mr. J. E. Bagnall; a large collection of British and foreign plants from the late Sir Benjamin Stone; the Sir George Kenrick Library of entomological works ; the Wilkins' ethnographical works; and numerous miscellaneous collections-a nearly complete collection of British birds (about 1,200 specimens) together with more than 14,000 nests and eggs, and one of the finest series. of nestling birds in downy plumage in existence, purchased and presented in 1924 by the Feeney Charitable Trustees, is on exhibition. There is also a collection of British and foreign freshwater and marine shells, formed by the late W. H. Whitlock, and a comprehensive land and freshwater shell collection obtained by the late P. T. Deakin. The scheme for the arrangement of the specimens was drawn up by the late Prof. F. W. Gamble. In addition, weekly nature study exhibits, mainly of a botanical nature, are arranged during the summer months. In 1912, an assistantkeeper for the Natural History Department was appointed.

\section{Award of the Eugenio Rignano Prize}

THe committee of judges for the award of the Eugenio Rignano prize for the best essay on "The Evolution of the Notion of Time" has recently announced its decision in a "Rapport de la Commission du Jury" dated October 1933. The prize, having a value of 10,000 lire, was established in 1930 as a memorial to E. Rignano, director of Scientia, who died in Milan on February 9 of that year. Competing essays were submitted by the end of 1932. No limitations were imposed as to mode of treatment, so that equal scope was afforded to scientific and philosophical aspects of time. A total of 35 essays were submitted, from the following countries: Italy (7), France (6), Germany (6), India (4), Great Britain (2), United States (2), Hungary (2), and one each from Austria, Switzerland, Russia, Luxembourg, South America and Australia. As a preliminary selection of essays of outstanding merit, the committee chose the papers of the following authors: E. Klein, W. Gent, G. Giorgi, H. Mehlberg, K. Sapper, J. Sivadjan, L. von Strauss, G. Windred and S. Zawirski. Of these, Prof. G. Giorgi of the University of Palermo and Prof. S. Zawirski of the University of Poznàn were finally selected as ex cequo recipients of the prize.

Consinerable space is devoted in the "Rapport" to a comparison of the various works submitted, and the widely varying nature of their treatment is remarked upon. The papers of $G$. Windred and $K$. Sapper receive extensive discussion in this connexion. Both papers are concerned with the historical development of the subject, but the points of view are respectively scientific and philosophical. The former author confines his attention chiefly to the problem of time as arising in mathematics and physics, tracing the origin and development of the various concepts from the time of Barrow and Newton up to the present day. The treatment of Sapper is essentially philosophical, and mainly concerned with temporal systems such as those developed by Kant and Leibniz, having but few connexions with mathematical or physical theory. These two methods of approach are representative of the widely different points of view of science and philosophy, even upon such a universal concept as that of time.

\section{Recent Advances in Inorganic Chemistry}

LECTURES, delivered last year before the Institute of Chemistry by Prof. G. T. Morgan, entitled "A Survey of Modern Inorganic Chemistry" have been made available to a wider audience by their publication by the Institute as a pamphlet which extends to more than one hundred pages (London : Institute of Chemistry). The three lectures thus provide chemists with a valuable monograph on the recent advances and tendencies of inorganic chemistry. Prof. Morgan describes, inter alia, the discovery and preparation of 'heavy' hydrogen, which some believe will prove so different from ordinary hydrogen as to be regarded almost as a new element, "in which case the organic chemistry of compounds containing this heavy isotopic hydrogen will become a fascinating but fearful study". Mention is made of the newer fundamental units of atomic structure, and attention is given to the electronic conception of chemical valency. The periodic groups of elements are then considered in turn with reference to the experimental successes of recent years in the discovery of new elements, new types of compounds, and new properties. Co-ordination compounds, in view of their general importance and of an interest which has resulted in many contributions to our knowledge of their behaviour having been made by Prof. Morgan and his pupils, receive due examination. The survey in this pamphlet disposes adequately of the suggestion that inorganic chemistry is anything other than a progressive and rapidly growing section of the science, and it is satisfactory that there are evident signs of a renewed interest in this branch of research among British chemists.

\section{North American Earthquakes}

Towands the end of January, two violent earth. quakes occurred in North America. The first on January 28 at 2.9 p.m. (7.9 p.m., G.M.T.) caused great damage in the Mexican port Acapulco and other towns in Guerrero. From the records at eleven stations, the epicentre is placed by the U.S. Coast and Geodetic Survey in lat. $15^{\circ} \mathrm{N}$., long. $99^{\circ} \mathrm{W}$. As this point is 140 miles due south of Acapulco, the earthquake must have been of great strength to damage houses in that city. The second occurred on January 30 at 3.16 a.m. (8.16 a.m., G.M.T.). According to the records from seven observatories, the epicentre lay in lat. $38 \cdot 8^{\circ} \mathrm{N}$., long. $118 \cdot 6^{\circ} \mathrm{W}$. This 